Canadian Journal of Higher Education Revue canadienne d'enseignement supérieur

Volume 47, No. 1, 2017, pages 61 - 79

\title{
Graduand Student Attributes: A Canadian Case
}

Heather Kanuka and Summer Cowley

University of Alberta

\begin{abstract}
The purpose of this qualitative case study was to gain insights into how academics understand undergraduate graduand attributes. The findings reveal some alignment in views about student attributes, including that they are engaged citizens, are self-directed, have imagination, are questioning, are flexible, display leadership, are problem solvers, and possess character. This consistency, however, does not include the spectrum of views on how these attributes are conceived and developed. The findings reveal a range of interpretations regarding the kinds and levels of understandings of how graduand student attributes are developed throughout an undergraduate program of study. The findings indicate that (i) a shared understanding does not exist on how academics construe student attributes, (ii) academics do not share common meanings about the core achievements of a higher education, or how these are developed through students' undergraduate programs, and (iii) student attributes tend not to be perceived as developing from the usual process of an undergraduate education.
\end{abstract}

\section{Résumé}

L'objectif de cette étude de cas qualitative était de mieux comprendre comment les étudiants de premier cycle sont perçus par les universitaires. Les résultats révèlent que les universitaires partagent certaines perceptions comme : l'engagement citoyen, l'autogestion, l'imagination, la curiosité, la flexibilité, le leadership, la résolution de problèmes et la grande force de caractère. Cependant, cette cohésion des perceptions exclut les points de vue 
quant à la conception et à la création de ces caractéristiques. En particulier, ces résultats révèlent des interprétations très différentes quant aux types et aux niveaux de compréhension sur la façon dont les caractéristiques des étudiants sont développées pendant un programme de premier cycle. Les données de cette étude de cas indiquent : 1) qu'il n'y a pas de consensus quant à la façon dont les universitaires interprètent les caractéristiques des étudiants; 2) que les universitaires ne partagent pas la même signification des réalisations fondamentales de l'enseignement supérieur ni de la façon dont ces réalisations sont obtenues lors du baccalauréat; et 3) que les caractéristiques des étudiants ne tendent pas à être perçues comme se développant pendant le processus habituel d'un enseignement de premier cycle.

\section{Introduction}

Since at least the 1980s, Canadian institutions of higher education have been under increasing pressure to justify their existence to employers, the government of the day, and accreditation bodies-not dissimilar, in many respects, to universities in Britain, the United States, and Australia (see, e.g., Clanchy \& Ballard, 1995; de la Harpe, Radloff, \& Wyber, 2000; Drummond, Nixon, \& Wiltshire; 1998; Leveson, 2000; Sumsion \& Goodfellow, 2004) -with non-professional degrees experiencing the most intense pressure (e.g., in sectors of the natural sciences, social sciences, and humanities). Past forms of pedagogical accomplishments continue to be not only necessary but paramount in programme aims and goals, including scholarly thinking, problem solving, scientific reasoning, and critical thinking. However, Barnett (2004) argued that these are increasingly being understood as insufficient for a higher education. Barnett further asserted that knowledge, skills, abilities, and competencies can no longer provide a platform for dealing with today's world. Indeed, under the current conditions, one goes forward because one has a self, character, disposition-i.e., "attributes"-that are adequate to not only survive but thrive in an uncertain future.

Some universities have addressed this imperative by describing the attributes of their undergraduate graduating/graduand students-or, quite simply, those "things" (e.g., qualities, characteristics, dispositions) that make a university student distinctive upon completion of their undergraduate programme of studies (Barnett, 1990; Barrie, 2006; Pitman \& Broomhall, 2009), sometimes also described as a set of meta-skills for the $21^{\text {st }}$ century (e.g., Coetzee, 2014). These might be attributes that prepare graduating students of bachelor programmes as mediators of social good in an unknown future, and they have included, for example, cultural awareness, ethical behaviour, respect for equality of opportunity, individual and civic responsibility, and/or an appreciation of cultural diversity (Barnett, 2011). More recently, student attributes have been perceived as a possible means of demonstrating how students of non-professional undergraduate degrees contribute to the Canadian economy by being employable graduates.

With few exceptions, Canadian universities (consistent with universities outside of Canada) have been unable to: (a) create a shared understanding of the attributes that students graduate with, (b) provide evidence that attributes are an outcome of a university education, (c) provide evidence that student attributes are a part of university curricula, and (d) develop attributes independent of their disciplines. As Toleman, Roberts, and 
Ryan have noted (2004; see also Bennett, Dunne, \& Carre, 1999), in an era of accountability, it is unsurprising that academics and stakeholders alike are sceptical about the claims that student attributes are an outcome of a university education, and that they question the relevance of such claims when evidence is not provided.

\section{Prior Research and Relevant Scholarly Literature}

Beginning in the early 1990s, Australia placed "personal transferable skills" on their higher education agenda, in recognition of the need for a flexible, adaptable workforce as society moved into the $21^{\text {st }}$ century and in response to the requirements of both employers and students that graduates of bachelor programmes be able to make an immediate contribution to any job situation (Kemp \& Seagraves, 1995). It is widely acknowledged that in the current context of rapid sociocultural, political, economic, and technological change, higher education institutions have a responsibility to prepare students who are able to manage and respond effectively to change and its inherent demands, challenges, and tensions (Diamond, 2011).

The Higher Education Council in Australia (1992) has described student attributes as being the knowledge, skills, and abilities that students acquire as a result of completing any undergraduate degree. The attributes are assumed to be applicable to contexts outside of their disciplines. Bowden, Hart, King, Trigwell, and Watts (2000) added that student attributes are qualities and understandings that a university community determines its students develop during their time with the institution. As importantly, while attributes include disciplinary and technical knowledge, they go beyond what has traditionally formed the core of most university courses and programs. They are the attributes that also prepare graduands as mediators of social good in an unknown future (Barnett, 2011; Barrie, 2007; Bowden et al, 2000).

While the literature reviewed for this study offers no single agreed upon definition of student attributes, there are several key features (Barrie, 2004, pp. 262-263):

1. They are developed regardless of the field of study or domain of knowledge. That is not to say that they are necessarily independent of disciplinary knowledge; rather, that attributes may be developed in various disciplinary contexts and are outcomes that in some way transcend disciplinary boundaries.

2. They are attributes to be looked for in a graduate of any undergraduate degree. They are not entry-level skills-rather, they are considered to be an important outcome of university-level learning experiences.

3. They are referred to as attributes rather than skills, knowledge, abilities, or competencies in recognition that as outcomes they encompass more than just skills, knowledge, abilities, or competencies.

4. The development of student attributes results from the usual process of higher education. That is, they are not a set of additional outcomes requiring an additional curriculum; rather, they are outcomes that can be reasonably expected from a higher education experience.

Barnett (2011) has described the notion of student attributes as the disposition and qualities required for university graduates to survive, and thrive, in a world of supercomplexity. Dispositions are necessary to enable students to go forward in the world; qualities are what give students a character. Dispositions are necessary, whereas quali- 
ties have some degree of optionality. Hence, undergraduate students graduate with a few dispositions but with many qualities. With respect to student attributes as employable skills (graduating for workplace readiness or not), Barnett asserts we need to discard this axiom, replacing it with students' will to learn (disposition) and their courage and openness (qualities).

Spanning more than two decades now, the literature and research on student attributes has become extensive. Reports of success by universities that have initiated student attributes have been, at best, uneven. In the UK, for example, Drummond, Nixon, and Wiltshire (1998) conducted a review of student attribute undertakings and concluded that the initiatives had been extraordinarily unsuccessful. While such a review appears not to have been conducted with more recent literature or beyond the UK, Barrie (2006) reported that even after a decade of such initiatives being implemented in Australian universities' curricula, reform is still required.

Perhaps on a more moderate note, the uptake of student attributes has been described as "slow," with assessment often noted as a key obstacle to integrating attributes into the curricula (de la Harpe, David, Dalton, \& Thomas, 2009). Lawson and colleagues (2012) determined from their research that one of the barriers to student attribute initiatives is that academics consider them, and their assessment, to be extra on top of their usual load and questionable with respect to sound educational practice. They concluded that implementation for such an initiative requires a strong, informed leadership alongside champions in units or departments. Elsewhere, student attributes have been described as being plagued by conceptual confusion, external pressures, and internal management issues that grossly underestimate the cultural, institutional, and policy changes required-all of which derail such institutional initiatives (Bennett et al., 1999). Green, Hammer, and Star (2009) described the problems experienced with attempts to implement such initiatives as resulting in a vexed situation, while others have described the implementation and uptake as patchy (Barrie, 2006). Green and colleagues (2009) further observed that while some universities have developed curriculum maps showing where the student attributes are acquired, this competency-based approach has tended to "foster superficial and ineffective approaches to the development of graduate attributes" (p. 18).

Sumsion and Goodfellow (2004) asserted that the problems with initiating and assessing student attributes revolve around the pervasive vagueness and inconsistency of the terminology and definitions, the lack of methodological or conceptual rigour, the paucity of evidence to suggest that they are, in fact, transferable across contexts and disciplines, and the political and managerialist agendas that drive many of these projects without providing resources to support and sustain significant pedagogical and curriculum change (p. 330). As importantly, while attributes might at first glance appear to be relatively "innocuous and uncontentious, to which many members of the higher education community can wholeheartedly subscribe, they have their roots in the contested territory of questions as to the nature of knowledge and the nature of a university" (Barrie \& Prosser, 2004, p. 244).

The research literature on student attributes appears to be largely based in Australia and to a lesser extent the UK. But is the literature and uptake of graduand student attributes transferable to the Canadian context? Using qualitative case study methodology, the purpose of this study was to gain insights into how Canadian academics understand graduand student attributes with respect to the following questions: (a) What attributes, 
if any, are developed through a university education? (b) What attributes, if any, distinguish students at research-intensive universities from those at other postsecondary institutions? (c) What attributes, if any, does the university curricula provide? (d) To what extent is there agreement on the definition(s) of graduate attributes?

\section{Theoretical Framework Guiding the Study}

As the section above illustrates, the body of literature on student attributes is substantive and varied, offering the possibility of guiding the data collection and analysis through a number of different theoretical and/or conceptual frameworks and lenses. This study used the conceptual framework developed by Barrie (2006). While other frameworks could have been used to guide the research, such as the matrix of "All Quadrants All Levels" (AQAL; Wilber, 2001) used by Haigh and Clifford (2011), Barrie's framework was selected because it was developed based on phenomenographic analysis arising from original data on student attributes, with the stated aim of understanding what is meant by attributes of students who have graduated with an undergraduate bachelor degree. Barrie's framework is premised on the assumption that academics have varied understandings of what student attributes are, students' core achievements, and how best to implement these attributes and achievements: "Such variations in conceptual understanding might imply, amongst other things, different valuing of the importance and relevance of addressing such outcomes" (2006, p. 219). Barrie (2006) has also noted that the lists of attributes are numerous, but beyond the simple documentation of such lists, scant information exists about the nature of the attributes. In particular, attributes need to go beyond mere lists, to reveal academics' understandings and intentions. Such knowledge can then inform how attributes might fit into the curricula. The framework developed by Barrie (2006) has four categories, which are of increasing complexity, with qualitatively distinct understandings of graduate attributes.

The first category is a precursory conception. In this category, academics understand graduate attributes as, primarily, a necessary precursor to the acquisition of skills and abilities. The understanding is that graduands possess the abilities and skills upon entry. These attributes, then, are seen as largely irrelevant. In particular, there is no relationship between these attributes (skills and abilities) and the students' program of study. Such attributes would include the three Rs, a basic knowledge of technology, and library skills.

The second category is a complement conception. In this category, academics understand attributes as useful additional skills that complement the students' programme of study knowledge. Here, the understanding is that there are personal skills that students develop alongside their disciplinary knowledge and that exist in addition to their program outcomes and goals. The key aspect of this category is that these attributes are viewed as independent of disciplinary learning outcomes but are conceived of as valuable and relevant to a university education.

The third category is a translate conception. In this category, academics consider attributes as student abilities that are transformed through disciplinary knowledge and application. Specifically, attributes are viewed as learning outcomes that graduand students possess in tandem with and parallel to their disciplinary knowledge. The attributes are assumed to be connected to personal attributes, cognitive abilities, and skills of application within the students' discipline of study and content knowledge. 
The fourth category is an enable conception. In this category, academics regard attributes as abilities that "infuse and enable all scholarly learning and knowledge. These abilities are seen as integral to disciplinary knowledge rather than being learning outcomes that sit alongside (either as independent or linked outcomes) discipline knowledge" (Barrie, 2006, p. 229). Attributes are not viewed as learning outcomes; rather, they encompass student learning as an integral aspect of discipline knowledge and are "the course of all scholarly knowledge and learning" (p. 229). This conception regards attributes as longer lasting than the other categories and more important than disciplinary knowledge; it is a reusable, holistic world-view framework that students use to develop their understandings and shape new knowledge in a manner that transcends the students' discipline.

There is a hierarchy of these conceptions in that each category is an increasingly complex notion of student attributes. Barrie (2006) has noted, for example, that categories one and two can be subsumed into category three, and category four is the most complex view. These categories do not reflect the discipline backgrounds, although a broader understanding about the nature of knowledge is relevant to an academic understanding of student attributes. As such, disciplinary conceptions of attributes are relational rather than causal.

\section{Methodology}

This study is conceptualized within the naturalistic paradigm as proposed by Frey (1994). A number of assumptions underpin this paradigm, including: (a) realities are multiple, constructed, and holistic; (b) knower and known are interactive and inseparable; (c) only time- and context-bound working hypotheses are possible; (d) all entities are in a state of mutual simultaneous shaping, so it is impossible to distinguish causes from effects; (e) inquiry is inherently value bound; and (f) the individual self is often divided and fragmented. These assumptions have come to provide an important basis for naturalistic research, and they underpinned the case study research design.

\section{Research Design}

Merriam (1998) defined a case study as "an intensive, holistic description of a single instance, phenomenon, or social unit" (p. 21). Case studies offer a number of well-known challenges (e.g., issues with validity, generalizability, value-laden documentation, and reporting of the findings). While other kinds of data collection were considered for this study, the case study was selected because of the need for descriptive data that (a) allow for multiple perspectives from the participants, (b) can be collected using a closed data collection process (e.g., surveys), and (c) permit an inductive approach. According to Thomas (2006), inductive approaches "allow research findings to emerge from the frequent, dominant, or significant themes inherent in raw data without the restraints imposed by structured methodologies" (p. 238). Advantages of the case study methodology that pertain to this study include the ability to (a) gain insights into complex interdisciplinary conceptions, grounded in the lived reality of the participants, (b) accommodate explorations of the unexpected and unusual, and (c) facilitate conceptual/theoretical development that can be used to gain insights into graduand student attributes within a Canadian context (Creswell, 1998; Gall, Borg, \& Gall, 1996; Hodkinson \& Hodkinson, 2001). 


\section{Selecting the Case}

It is contended that the case selected for this study (the University of Alberta) is characteristic of research-intensive universities across Canada. It is a member of the U15 (Canada's 15 research-intensive universities), with academic hires who have been employed and/or earned their highest degrees at similar universities in Canada, bringing with them many norms and practices from their originating institutions. Likewise, many other similar institutions across Canada have hired University of Alberta graduates/academics, further blurring distinctions between institutions. Moreover, the U15 was formed based on similarities between and mutual interests of Canada's researchintensive universities. Finally, the University of Alberta is in a province where challenges by the government and business communities have brought graduand student attributes to the foreground, including, (a) questioning the merits of degree-granting postsecondary institutions, especially the relevance of non-professional degrees, and (b) duplication of degrees across provincial postsecondary institutions, arising from two major colleges that have recently transitioned to become universities. Since those transitions, questions have been asked: What makes a research-intensive university unique/different from a teaching-intensive university, and why should both kinds of universities be funded? The response from research-intensive universities in Alberta has typically been that students from such universities graduate with a different set of attributes, based on being taught by researchers in the disciplines (e.g., students are exposed to the teaching/research nexus), versus instructors with proficiency and expertise in teaching the discipline. Perhaps unsurprisingly, this response has been challenged. Proving and/or disproving these claims is difficult, as doing so would require longitudinal research as well as agreed upon operating definitions of student attributes. Acknowledging these limitations, this qualitative case study begins by gaining insights on how academics in a research-intensive university understand their undergraduate graduand student attributes.

\section{Data Collection}

Data collection involved the use of individual, in-depth, semi-structured interviews. Guided by the research objectives of this study, participants were asked to share their views on the following four questions:

1. What student attributes (qualities, dispositions), if any, are developed through [your] university's education?

2. What student attributes (qualities, dispositions), if any, distinguish [your university] students from other students at other universities (tertiary institutions)?

3. What student attributes (qualities, dispositions), if any, does a university education (e.g., in the program curricula) provide students?

A fourth question was asked, with the aim of gaining insights about the degree of consistency that exists with respect to how attributes are understood.

4. What is your definition of [attributes]?

Participants. Participants were selected to ensure equal representation from disciplines in the main quadrants of Canadian federal research funding, the tri-council (natural sciences and engineering; social sciences and humanities; health sciences). Twenty-one academics (seven from each Canadian tri-council area) were initially asked to partici- 
pate. Participants were associate or full professors with past and/or present experience on university-wide curriculum committees and were recognized for their contributions to and/or interest in teaching and learning (e.g., received teaching awards, contributions to curriculum reform). As the data were initially being analysed and reviewed by the peer debriefers, topics and categories were emerging but with insufficient consistency. Hence, a decision was made to add three more participants in each disciplinary category, resulting in a total of 30 participants.

Participants were invited through email to participate and were provided with the interview questions in advance of the interview, again via email. Data were recorded by typing in responses directly on a computer. Member checks were conducted following each interview, based on the typed interview notes, and again when the data were analyzed/ categorized.

Trustworthiness of the data. Trustworthiness of the data was achieved through multiple views verification (Creswell, 1994). To ensure trustworthiness of the data in this naturalistic inquiry, corroborating evidence was used. Specifically, structural corroboration was achieved by testing data and interpretations against others' views to be certain that there were no internal conflicts or contradictions (Guba, 1981). In this study, corroborating evidence for determining data trustworthiness was provided through consistency between the lens of the participant interviews (data saturation), peer-debriefing, and member checks.

\section{Data Analysis}

The interview data were analyzed using the constant comparison techniques of grounded theory (Strauss \& Corbin, 1990), with emerging themes and categories guided by Barrie's (2006) conceptual framework. To facilitate the identification of categories arising around the framework, the think aloud transcripts (Gibbs, 2007) were first read reflectively to identify relevant categories. This involved a counting process for category identification that was conducted by Heather Kanuka, the principal researcher, followed by two peer debriefs before member checks were conducted. Phrases within the transcripts were categorized, and initial codes were identified and labelled. Code labels emerged as a result of a direct phrase or use of language by participants. For example, some participants used the word "self-directed" to describe the need for students to be autonomous and responsible for their own learning. This type of coding, referred to as in vivo codes, keeps the exact words used by participants (Creswell, 2007). By using in vivo codes in the analysis process, we ensured that conceptions and understandings of the participants' meanings stayed as close as possible to their own words, thereby capturing the essence of what the participants stated in the interviews. A second review of the transcripts allowed categories to be further refined and interconnected. The data were reassembled into groupings based on relationships and patterns with the categories identified in the data. The consistency and frequency of the identified themes across the participants were also established. The codes that emerged from the data were then (a) organized into attribute clusters and (b) categorized using Barrie's (2006) conceptual framework of how graduate student attributes are developed and implemented. Table 1 provides a synopsis of the results. 
Table 1.

Attribute cluster summary $(n=30)$ and conception categories

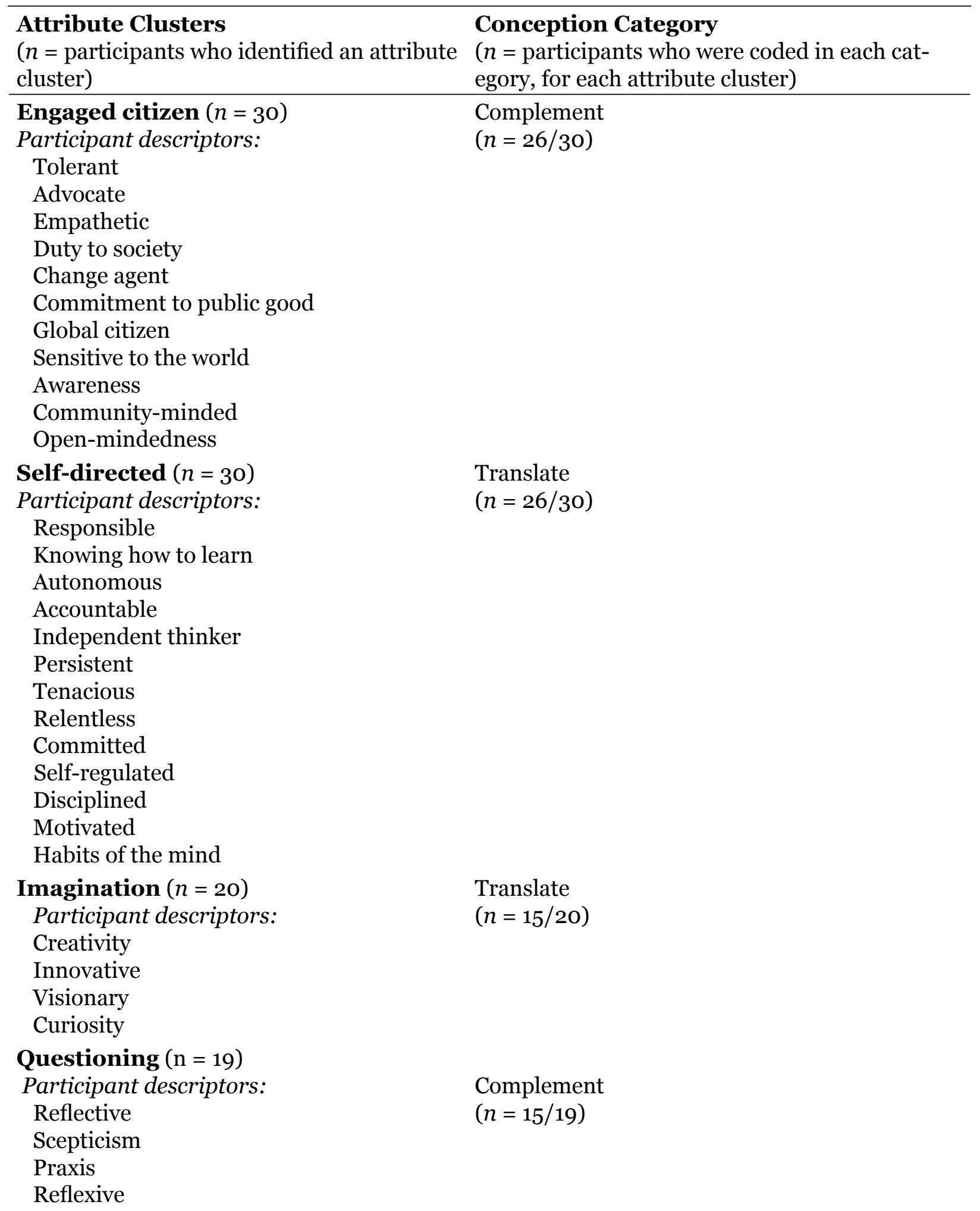




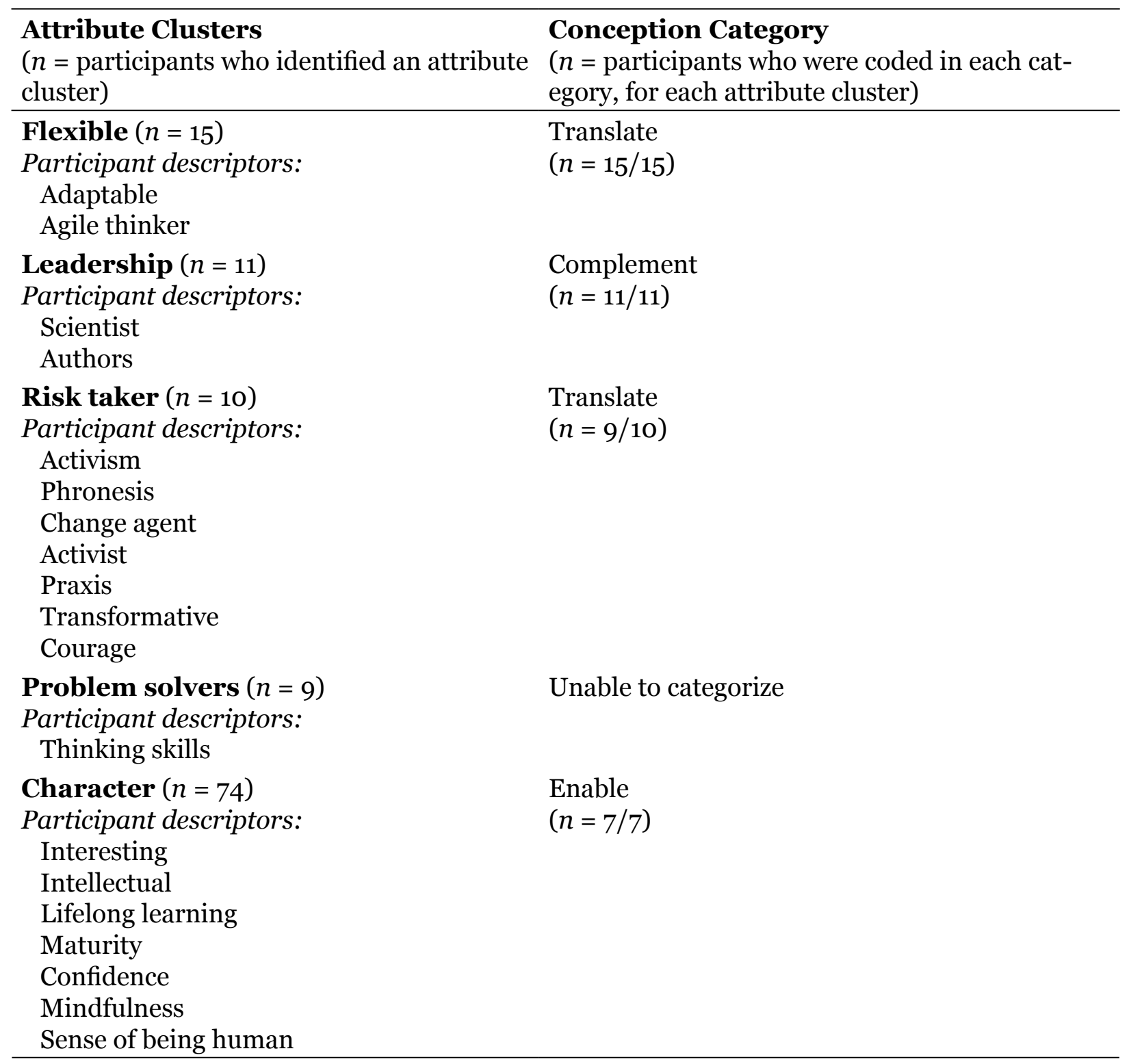

Following are the categorized data, alongside representative participant comments for each attribute cluster and conception category.

Engaged citizen. The first and most frequently cited student attribute was engaged citizen (30/30). As Table 1 illustrates, however, it was also the attribute with the second widest definition. Although the cluster of engaged citizenship was discussed by all participants, not everyone thought it was desirable as an attribute. Two participants did not think citizenship is, or should be, an attribute and were quite ardent in their position. An example of rather strong opposition to this attribute illustrates this point:

Engaged citizenship is the most egregious [nonsense] I have heard of. I don't know what it means and is political [nonsense]. What do you want as a citizen? You want someone who places a priority on the good of society that they belong to. Can't say this is a priority over their own good, but has to be on their radar. So how does a Uni- 
versity play into that? I would argue that "engaged" is redundant to "citizenship"-it is already part of citizenship. ... What we have in a university are the role models for standing up to the "band." The idea of Dave Schindler [environmentalist] with the deformed fish saying, "I think we have a problem here," and Paul Woodard [a land fire specialist], asking, "What's causing this?" Having academics like Paul and Dave stand up to the government and its policies, with job loss as a threat, is what gives our students some understanding of what citizenship looks like.

The other participant asserted that "citizen" (and related forms of the word) was not an appropriate word choice:

It [citizenship] is a legal term that defines someone to a particular state, and presumably we graduate students that are not all citizens in Canada. Rather, as an attribute, we talk about "civically engaged humans." . . . and "civically engaged" refers to someone who belongs to a political party.

When asked about how this attribute is developed, participants overwhelmingly fell into Barrie's (2007) complement category: something that complements the student's program and is independent of disciplinary learning outcomes. Following is a comment illustrating how most participants understood citizenship:

I think there are individual activities, courses that facilitate students becoming engaged citizens. So, for example, taking a community service learning course or here in law school a poverty class-it has 10 working hours/week in legal aid or the clinic. These additional activities go some way in helping to be an engaged citizen. [Bold added to highlight the "conception" category alignment.]

Self-directed. As with engaged citizen, this attribute cluster was raised by all participants (30/30). And, as with engaged citizen, definitions were wide and varied, with decisively distinct understandings of how they were conceived (see Table 1). Following is a representative comment on passion being an attribute of a successful student, tied to self-direction:

A university education is where students choose the life of the mind, and passion is part of the mind ... passion is the self-motivation that will see them move successfully through their program.

When asked about how this attribute is developed, the majority of participants fell into the translate category: students are viewed as going through a transformation that results in becoming self-directed, and this is viewed as an outcome that graduand students possess in combination with their disciplinary knowledge. The attributes are assumed to be connected to personal attributes, cognitive abilities, and skills of application within the students' discipline of study and content knowledge. Most participants explained self-directed learning as a requirement to succeed in programs of study; the following is representative:

It is important for students to have the ability to navigate a hostile environment and take control of their own education. So, take a science student. They are one of roughly 3,000 students. We've got more demand than space; they have to figure 
out how to get into that space to get through their program. Otherwise they drift along, eventually becoming a non-completion statistic ... drop out, flunk out, time out. [Bold added to highlight the "translate" category alignment.]

Imagination. Many participants also talked about imagination being a graduand student attribute (20/30). Participants tended to associate this attribute cluster with "thinking big." When asked how this attribute is developed, most fell into the translate category, where students are viewed as going through a transformation, arising from attending a "research-focused" institution. This is viewed as an outcome that graduand students possess in combination with their disciplinary knowledge. The attributes are assumed to be connected to personal attributes, cognitive abilities, and skills of application within the students' discipline of study and content knowledge. The following is a representative comment:

Curiosity ties into the research component of a university education. By being exposed to research in their program of study, it inspires students' imagination and curiosity to the frontiers of the field. It's a depth-the deep curiosity ... it gets students excited, it drives them. This student drive gets fed by our leading-edge research. [Bold added to highlight the "translate" category alignment.]

Questioning. Many participants talked about questioning as being an important graduate student attribute (19/30). Participants displayed good agreement in the definition of this attribute, using words similar in meaning to describe the essence of questioning. One participant observed that questioning (and associated terms) is not a new construct of a modern university; it dates back to the Greek notion of Socratic questioning and rhetoric-in the sense that graduates should be able to question and debate:

Students should be able to participate in constructive and analytical debates, orally and written-to present their argument on issues. Not just accept, but to question. And questioning is not enough; one must also answer and be prepared to debate and engage in deliberative inquiry.

It should be noted that not everyone agreed with questioning alone, per se; as one participant noted:

Asking the right questions is more important than the answer. We don't know the truth; we are in search of it. And even when we find a truth, it is not enough: "non satis scire" [translation: to know is not enough] . . . As researchers, when we question, the chances of becoming a renaissance person is more likely-we provide wider opportunities, experiences, and exposure to research to our students.

When asked about how this attribute is developed, participants generally fell into the complement category, describing questioning as something that complements the students' program and is independent of disciplinary learning outcomes. The following is a representative view of how questioning is developed:

So questioning is something that our students develop-I think not part of their program of studies, but in addition to their program of studies. We teach them this ... no, no, not stated as a learning outcome... This is for 
sure one of the most valuable aspects [of a university education] that our students go away with. [Bold added to highlight the "complement" category alignment.]

Flexible. Some participants also discussed the need for students to develop flexibility as an attribute (15/30). The following is an example of how one academic described this attribute:

So this process has something to do with students becoming comfortable with uncertainty ... comfortable with non-black and whites. Once they get beyond needing a right answer ... that's an important step for the real world as well. So "adaptable" is right but "supercomplexity" is wrong. When I hear this I think this is complex but knowable. I'm not sure in science if anything is ever knowable. So adapting to a world of uncertainty is a necessity.

When asked about how this attribute is developed, those participants that stated flexibility as an attribute fell into the translate category, whereby students are viewed as going through a transformation that results in becoming flexible; this was viewed as a quality that graduate students possess in combination with their disciplinary knowledge. The attributes were assumed to be connected to personal attributes, cognitive abilities, and skills of application within the students' discipline of study and content knowledge. Some participants observed that we need to prepare our students for an unknown future by preserving knowledge and creating new knowledge:

We create students who can face both as part of the undergraduate experience-so, we educate our students to be flexible and [to have] an openness to opportunity ... and [be] agile thinkers. [Bold added to highlight the "translate" category alignment]

Leadership. About a third of the participants stated that leadership is a graduate student attribute (11/30). Many saw a university as training the next generation of leaders, scientists, and authors. As one participant mused:

Each student can also realize their dreams, with a greater range of intellectual thought ... much of that is knowledge and discourse. It is all about opportunity here; opportunity to imagine being a leading scientist or author in addition to "just leaving with their degrees." [Bold added to highlight the "complement" category alignment]

This comment also illustrates that faculty participants understand leadership as a complement to a degree-as a useful addition that complements the students' program of study knowledge, and something with value and relevance.

Risk taker. Some faculty participants also believed that a university education cultivates risk takers as a graduand attribute (10/30). Understandings of this attribute were varied, as were the words describing it (see Table 1). One participant who noted this as an attribute ruminated about the notion that knowing needs to be followed by action, indicating this requires some degree of risk taking. Another participant expressed this as practical wisdom, and another made the point of this attribute through quoting a poem by Rudyard Kipling: 
"If you can make one heap of all your winning, and risk it on one turn of pitchand-toss-and lose, and start again at your beginning. And never breathe a word about your loss." This is what I mean by the kind of risk taking students acquire as a result of their undergraduate studies.

When asked how this attribute is developed, participants generally fell into the translate category, with students viewed as going through a transformation arising from the need to go beyond mastery and competency-based learning of knowledge, skills, and abilities in their studies. The following is a representative comment:

A university education forces students to take risks in their thinking. Just learning the material is not good enough. [Bold added to highlight the "translate" category alignment.]

Problem solving. Rather surprisingly, few participants commented on problem solving as an attribute (9/30). When it was mentioned, this was typically in conjunction with professional student attributes (e.g., problem-based learning in the field of medicine). On this attribute, there was considerable disparity regarding the value of problem solving. Some participants expressed the need for students to be problem solvers (mostly in the fields of engineering, medicine, and health sciences), while others viewed problem solving as a necessary skill to develop but insufficient as an attribute for a university graduate (mostly in the fields of social sciences and humanities). Given that many participants did not view this as an attribute (but rather as a skill to be taught), it is difficult to categorize how participants perceived this as being developed.

Character. Scattered throughout the interviews were comments relating to the influence the university has on its students' character (7/30). A representative comment follows:

While we have no coherent idea of what critical thinking is in our university, there is lots of extrinsic evidence, such as course assignments, that our graduates actually "think" about the things learned in a university; I believe this, by association, makes them an "interesting" adult-or a person "of" character and "with" character.

Although only a few participants described character as an attribute, when asked how it is developed, respondents regarded it as something that is integrated throughout an undergraduate program, putting them into the enable category. While this attribute was understood as connected to disciplinary knowledge, the important aspect for participants was that it transcends disciplinary knowledge, changing students' world views. As one participant noted:

Yes, something happens to students, well of course not all students, but, well, I'd say most students . . . they leave university being different, and more than just thinking different. They "are" different. More than a maturity thing. A change in their character. Perhaps naïve on my part stating this with no evidence, but after 30 years in the academy I feel I can say with some authority, a change of character happens when things go right for students during their four years here. [Bold added to highlight the "enable" category alignment] 


\section{Discussion}

In most respects, the results in this study are consistent with much of the prior research. For example, the results suggest that the academics in this university have varied understandings about graduand student attributes, a finding that is consistent with prior research (e.g., Barrie, 2006; Fraser \& Thomas, 2013). Acknowledging the consistency with prior research, a noteworthy finding in this study is that the graduate attributes identified by the participants were understood as developing in students without curricular intervention and/or curricular intent.

Also similar to other research (e.g., Barnett, 1990; Pitman \& Broomhall, 2009), many participants in this study were indifferent about the notion of student attributes, critical about institution-wide agreement, and unconvinced that there was anything unique about graduates from other research-intensive universities in Canada. Many participants expressed views similar to those described in Kember's (2009) research-i.e., that it could certainly plausibly be interpreted "as an act of faith [to believe] that the traditional model of university education is capable of nurturing graduates with capabilities" (p. 39). Although most participants agreed that graduand student attributes are useful in articulating the value of a university education, most do not believe they can be measured as outcomes. Without actual data, many participants in this study said they consider student attributes outside the scope of their mandate and expertise. Illustrative of this point is a follow-up email from one of the faculty participants:

Further to my position: Although I can talk about, and attempt to enforce, scholarly behaviour (the responsibility of scientists to lead an evidence-based life, following the scientific method, proper credit for ideas, etc.) I can't speak to issues like citizenship. Even if I knew what that meant, you would actually have to provide me with a compelling argument as to why I should support it. I'm an unashamed pro-Enlightenment / objectivist guy, and think there are in fact philosophical best practices. I'm also not responsible for the ultimate moral disposition of the students who graduate. ... A university can attest to a certain level of subject competence. To the extent that we can define, teach (somehow), and measure GSAs then we can put them into our mandate. . . . Of course I think GSAs are important but I am sceptical that the academic community has the ability to develop a curriculum that develops these attributes. Especially since I don't see coherent programmes across campus. If we can't plan for content and skills, how do we expect to develop these GSAs?

The data in this study also reveal variation in how academics construe their views about student attributes. Using Barrie's (2006) conceptual framework, the results of this study indicate that there is sufficient consensus about what attributes students should have upon graduation (i.e., the attribute clusters); hence, a list of institutional attributes could be assembled. However, the results of this study also indicate that it would be difficult, if not impossible, to implement the attributes. Specifically, once the attributes were identified, the next steps would be to establish meanings and determine where the attributes would be mapped into the curricula. This would require curriculum reform. Again, as in other universities, outside of Canada, such curriculum reform is unlikely to be achievable, given the varying ways in which academics understand attributes. As Barrie noted: 
Holding a Complement (level 2) conception ... in an already crowded curriculum typically dominated by content, the fostering of such learning outcomes will always be secondary to the teaching of discipline knowledge. As such any curriculum innovation will be inherently vulnerable to displacement by curriculum pressures to prioritise disciplinary content. Moreover, calls for the inclusion of such outcomes amongst the learning outcomes of the course will be seen as an imposition of additional work by academics. (p. 235)

Fraser and Thomas (2013) noted further that the lack of structure (e.g., core units) with respect to prerequisites in non-professional degrees (e.g., arts), alongside the differences in subject majors and minors, make it difficult to provide opportunities to develop attributes for students as they move through their studies.

Finally, the participants in this study did not conceptually untangle generic, core, key enabling, and transferable professional skills, as well as capabilities and competencies. According to Green and colleagues (2009; see also Barrie, 2005), skills, capabilities and competencies are not the same as attributes. In order to successfully implement graduand student attributes, conceptual clarity and consensus are required.

With respect to the conceptual framework used in this study, it was noted in the methodology section that an advantage of the case study methodology is the potential contribution to conceptual/theoretical development. In this regard, the findings of this study build on, and contribute to, Barrie's (2006) conceptual framework. In addition to providing further evidence that academics tend to construe student attributes within the four hierarchical categories of precursory, complement, translate, and enable, the findings of this study reveal that academics perceive the development of student attributes as occurring without direct curricular intervention (e.g., curricular mapping).

\section{Conclusions and Précis}

Graduand student attributes speak to value and moral worth (Pitman \& Broomhall, 2009) and can therefore suggest that institutions of higher education are distinct from other degree-granting providers. In this view, the education a university provides has to be understood in terms not only of knowledge, skills, abilities, or competencies, but also of human qualities, character, and dispositions-or "attributes." Prior research has revealed that a fundamental underpinning for the successful implementation of graduand student attributes is a shared understanding of student attributes that manifest in some form by the time students complete their undergraduate programmes of study (Barrie \& Prosser, 2004). Similar to prior research on student attributes, the data from this case study indicate that there is limited evidence to suggest a shared understanding exists on how academics construe student attributes.

As a closing reflection, after reading widely in the literature, participating on related institutional curriculum committees, and collecting data for this study, we find it difficult to understand how graduand student attributes could be successfully identified and integrated into the curricula in large, research-intensive universities in Canada. Evidence of successful implementation requires (a) agreement among academics and between disciplines on terminology and definitions of graduand student attributes, (b) campus-wide policy and leadership from senior administration, (c) resources to integrate attributes 
into the curricula and training of instructors to implement them, and (d) resources for longitudinal research to follow students throughout their programs of study and gather evidence that graduands acquired the attributes as a result of their programs of study, rather than already possessing those attributes. As we reviewed the prior research on student attributes and the institutions that claim to have implemented graduand student attributes, we could not find credible and/or rigorous research conducted by researchers and/or institutions that provided substantive evidence-beyond the "perceptions" of academics - that graduand student attributes develop from a student's program of study. Longitudinal research is needed to track and document the attributes that students (may) acquire throughout their undergraduate programs, including where in their programs of study these changes occur (e.g., what kinds of courses facilitate the development of student attributes) and when (e.g., in what year). Additionally, research from the students' perspective, as well as the perspective of those who employ the students, is needed to confirm (or not) consistency with the research on the development of student attributes in undergraduate programs.

\section{References}

Barnett, R. (1990). The idea of higher education. Buckingham, UK: Society for Research into Higher Education \& Open University Press.

Barnett, R. (2004). Learning for an unknown future. Higher Education Research \& Development, 23(3), 247-260.

Barnett, R. (2011). Being a graduate in the twenty-first century [PowerPoint presentation to the University of Alberta]. Retrieved from https://uofa.ualberta. ca/-/media/ualberta/centre-for-teaching-and-learning/symposium/imagininguniversity-2011/being-a-graduate-in-the-twentyfirst-century-univ-of-alberta-april-2011. ppt

Barrie, S. C. (2004). A research-based approach to generic graduate attributes policy. Higher Education Research \& Development, 23(3), 261-275.

Barrie, S. (2005). Rethinking generic graduate attributes. Higher Education Researh \& Development (HERDSA News), 27(1), 1-6.

Barrie, S. C. (2006). Understanding what we mean by generic attributes of graduates. Higher Education, 51, 215-241.

Barrie, S. C. (2007). A conceptual framework for the teaching and learning of generic graduate attributes. Studies in Higher Education, 32(4), 439-458.

Barrie, S. C., \& Prosser, M. (2004). Generic graduate attributes: Citizens for an uncertain future. Higher Education Research \& Development, 23(3), 243-246.

Bennett, N., Dunne, E., \& Carre, C. (1999). Patterns of core generic skill provision in higher education. Higher Education, 37, 71-93.

Bowden, J., Hart, G., King, B, Trigwell, K., \& Watts, O. (2000). Generic capabilities of ATN university graduates. Canberra, Australia: Department of Education, Training and Youth.

Clanchy, J., \& Ballard B. (1995). Generic skills in the context of higher education. Higher Education Research and Development, 14(2), 155-166. 
Coetzee, M. (2014). Measuring student graduateness: Reliability and construct validity of the Graduate Skills and Attributes Scale. Higher Education Research \& Development, 33(5), 887-902. doi:10.1080/07294360.2014.890572

Creswell, J. W. (1994). Research design: Qualitative and quantitative approaches. Thousand Oaks, CA: Sage.

Creswell, J. W. (1998). Qualitative inquiry and research design: Choosing among five traditions. London, UK: Sage.

Creswell, J. W. (2007). Qualitative inquiry and research design: Choosing among five traditions (2nd ed.). Thousand Oaks, CA: Sage.

de la Harpe, B. David., C. Dalton, H., \& Thomas, H. (2009). Are confidence and willingness the keys to the assessment of graduate attributes? Proceedings of the ATN Assessment Conference, RMIT, Melbourne.

de la Harpe, B., Radloff, A., \& Wyber, J. (2000). Quality and generic (professional) skills. Quality in Higher Education, 6(3) 231-243.

Diamond, I. (2011). Challenge and change in further education: A commentary by the teaching and learning research programme. London, UK: University of London. Retrieved from https://www2.warwick.ac.uk/fac/soc/ier/people/abrown/publications/ fe_commentary_final.pdf

Drummond, I., Nixon, I., \& Wiltshire, J. (1998). Personal transferrable skills in higher education: The problems of implementing good practice. Quality Assurance in Education, 6(1), 44-58.

Fraser, K., \& Thomas, T. (2013). Challenges of assuring the development of graduate attributes in a Bachelor of Arts. Higher Education Research \& Development, 32(4), 545560.

Frey, L. (1994). The naturalistic paradigm: Studying small groups in the postmodern era. Small Group Research, 25, 551-577.

Gall, M. D., Borg, W. R., \& Gall, J. P. (1996). Educational research: An introduction (6th ed.). White Plains, NY: Longman.

Gibbs, G. (2007). Analysing qualitative data. London, UK: Sage.

Green, W., Hammer, S., \& Star, C. (2009). Facing up to the challenge: Why is it so hard to develop graduate attributes? Higher Education Research \& Development, 28(1), 17-20.

Guba, E. G. (1981). Criteria for assessing the trustworthiness of naturalistic inquiries. ERIC/ECTJ Annual Review Paper, 29(2), 75-91.

Haigh, M., \& Clifford, V. A. (2011). Integral vision: A multi-perspective approach to the recognition of graduate attributes. Higher Education Research \& Development, $30(5), 573-584$.

Higher Education Council (HEC) Australia (1992). Achieving Quality. Higher Education Council, National Board of Employment, Education and Training. Canberra: Australian Government Publishing Service. 
Hodkinson, P., \& Hodkinson, H. (2001, December). Strengths and limitations of case study research. Paper presented to the Learning and Skills Development Agency Conference: Making an Impact on Policy and Practice, Cambridge, UK.

Kember, D. (2009). Nurturing generic capabilities through a teaching and learning environment which provides practise in their use. Higher Education, 57, 37-55.

Kemp, I., \& Seagraves, L. (1995). Transferable skills-can higher education deliver? Studies in Higher Education, 2O(3), 315-328.

Lawson, R., Taylor, T., Herbert, J., Fallshaw, E., French, E., Hall, C., Kinash, S., \& Summers, J. (2012, July). Strategies to engage academics in assuring graduate attributes. Paper presented at the Eighth International Conference on Education, Samos, Greece. Retrieved from http://eprints.qut.edu.au/52630/2/52630.pdf

Leveson, A. (2000, June). Disparities in perceptions of generic skills: Academics and employers. Industry and Higher Education, 157-164.

Merriam, S. (1998). Qualitative research and case study applications. San Francisco, CA: Jossey-Bass.

Pitman, T., \& Broomhall, S. (2009). Australian universities, generic skills and lifelong learning. International Journal of Lifelong Education, 28(1), 439-458.

Strauss, A., \& Corbin, J. (1990). Basics of qualitative research: Grounded theory procedures and techniques. Newbury Park, CA: Sage.

Sumsion, J., \& Goodfellow, J. (2004). Identifying generic skills through curriculum mapping: A critical evaluation. Higher Education Research \& Development, 23(3), 329346.

Thomas, D. (2006). A general inductive approach for analyzing qualitative data. American Journal of Evaluation, 27(2), 237-246.

Toleman, M., Roberts, D., \& Ryan, C. (2004). Retrofitting generic graduate attributes: A case-study of information systems undergraduate programs. Issues in Informing Science and Information and Technology, 1, 625-635. Retrieved from http://proceedings. informingscience.org/InSITE2004/o88tolem.pdf

Wilber, K. (2001). The theory of everything. Boston, MA. Shambhala.

\section{Contact Information}

Heather Kanuka

University of Alberta

hakanuka@ualberta.ca

Heather Kanuka is a professor in the Department of Educational Policy Studies, Faculty of Education, University of Alberta.

Summer Cowley is a master's student in the Department of Educational Policy Studies, Faculty of Education, University of Alberta. 